\title{
INFLUENCIA DE LA PRÁCTICA DE ORDEÑO SOBRE EL RECUENTO DE CÉLULAS SOMÁTICAS (RCS) Y UNIDADES FORMADORAS DE COLONIAS (UFC) EN LECHE BUFALINA
}

\section{INFLUENCE OF MILKING PRACTICES ON SOMATIC CELL COUNT (SCC) AND COLONY FORMING UNITS (CFU) IN BUFFALO MILK}

\author{
Sergio A. Morales Morales ${ }^{1}$, Nélida Rodríguez ${ }^{2}$, Juan Fernando Vásquez ${ }^{3}$, Martha Olivera Ángel ${ }^{4}$
}

\begin{abstract}
${ }^{1}$ IAP. M.Sc (c). Ciencias Animales, Grupo CENTAURO, Universidad de Antioquia, Colombia, e-mail: sergiomorales80@yahoo. es; ${ }^{2}$ MV, M.Sc, Ph.D. Docente e investigador, Grupo CENTAURO, Universidad de Antioquia, Medellín, Colombia, e-mail: nelidarodriguez48@gmail.com; ${ }^{3}$ MV, M.Sc, Investigador Grupo Biogénesis, Cooperativa Colanta, Medellín, Colombia, e-mail: jufevaca@gmail.com; ${ }^{4}$ MV, Dr. Agr Sc. Docente e Investigador, Grupo Biogénesis, Universidad de Antioquia, Medellín, Colombia, e-mail: syngamia@gmail.com.
\end{abstract}

Rev. U.D.C.A Act. \& Div. Cient. 17(1): 189-196, Enero-Junio, 2014

\section{RESUMEN}

Una adecuada rutina de ordeño tiene como fin disminuir el riesgo de contaminación de la leche. El presente trabajo indagó sobre los factores de riesgo que la práctica de ordeño puede tener sobre la calidad higiénica (UFC) y sanitaria (RCS) de leche bufalina, en tanques de leche del Magdalena Medio y costa Atlántica de Colombia. Para este propósito, se aplicó una lista de chequeo para sondear las actividades pre-ordeño, durante el ordeño y pos-ordeño, como posibles factores que influyen sobre los recuentos de UFC y RCS, en 23 hatos bufaleros. Se tomaron muestras de leche para medición de recuentos de bacterias, encontrando un promedio de $182,6 \pm 295,4 \times 10^{3} \mathrm{UFC} / \mathrm{mL}$ y para RCS, un promedio de $137,1 \pm 158,9 \times 10^{3} \mathrm{cs} / \mathrm{mL}$. Como factores protectores para calidad higiénica, se detectaron: estado sanitario del piso, el lavado de ubre y pezones, la frecuencia de lavado de manos, duración de pre-sellado, secado de pre-sellado, uso de filtro desechable, ordeño de búfalas positivas a mastitis al final y enfriamiento a $4^{\circ} \mathrm{C}$, en menos de 2 horas. Los factores de riesgo asociados a altos recuentos de UFC son: ausencia de lavado de manos OR 1,7 ( $p=0,003)$, ausencia de pre-sellado OR $1,07(p=0,003)$, poco uso de filtro desechable en cantina y tiempo entre el ordeño y vaciado a tanque de frío OR 1,7 ( $p=0,003)$; el factor de riesgo asociado a altos RCS es el material para secado de manos OR $1,04(p=0,002)$.

Palabras clave: RCS, UFC, Búfalo, prácticas de ordeño.

\section{SUMMARY}

The aim of an appropriate milking procedure is to reduce the risk of milk contamination. This work studied the risk factors in milking practices that affect the hygienic (CFU) and sanitary quality (SCC) of milk tanks from the "Mid Magdalena" and "Atlantic Coast" regions of Colombia. A checklist that explored pre-milking, milking and post-milking activities as possible factors influencing CFU and SCC in 23 buffalo farms was applied. On the day of the checklist survey, samples of cold milk in tank to test for bacteria counts were taken, finding an average of $182.6 \pm 295.4 \times 10^{3} \mathrm{CFU} / \mathrm{mL}$; also tested for SCC was tested and an average of $137.1 \pm$ $158.9 \times 10^{3} \mathrm{sc} / \mathrm{mL}$ was found. As hygienic quality protective factors generating a low CFU count in bulk tank floor tidiness, udder and teat washing, hand washing frequency, duration of teat sealing, wiping of sealing dip, presence of filter in the milk container, the use of disposable filters, milking the buffalo cows positive for mastitis towards the end of the milking process and cooling the milk at $4^{\circ} \mathrm{C}$ in less than 2 hours after milking was identified. The risk factors associated with high CFU counts are the absence of hands washing with OR (Odds Ratio) $1.7(p=0,003)$, teat sealing with OR 1.07 $(p=0,003)$, use of disposable filter in milk container, and the period of time between milking and tank storage with OR $1.83(p=0.4)$. The risk associated with high SCC's is material for hand drying with OR $1.04(p=0.002)$.

Key words: SCC, CFU, Buffalo, milking practices. 


\section{INTRODUCCIÓN}

En Colombia, la lechería bufalina, con un estimado de 170.000 cabezas (Patiño, 2011), representada por las razas Mediterránea, Murrah, Jafarabadi y sus cruces, se posiciona como una alternativa pecuaria promisoria, tanto a nivel de grandes como de medianos y pequeños productores ganaderos. En áreas tropicales y subtropicales, los búfalos tienen gran importancia, ubicando a Pakistán como el mayor productor de leche de búfala, a nivel mundial, con un aporte cerca del $60 \%$ de la producción (Cervantes et al. 2010). La leche de búfala contribuye con el $12,8 \%$ del total de la leche que se produce en el mundo, para consumo humano (FAO, 2010). En Colombia, la mayor concentración de ganaderías bufalinas se encuentran en el trópico bajo o zona cálida y húmeda, siendo las regiones del Magdalena Medio y la Costa Atlántica los mayores centros de acopio de leche por la industria láctea y representa la leche mejor pagada por litro \$ 0,78USD, en comparación con la leche de vaca \$0,5USD (COLANTA, 2012) y un promedio de 4,64Kg/búfala/día (Hurtado et al. 2005a), similar a lo reportado por Vásquez, (2005).

El Decreto 616 de 2006 describe la práctica de ordeño para las especies bovina, bufalina y caprina (artículo 6), las condiciones de conservación, el tratamiento de la leche y también los requisitos microbiológicos (artículo 19). Este decreto es además la reglamentación básica y guía para la certificación de las Buenas Prácticas Ganaderas (BPG).

La calidad higiénica y sanitaria está determinada por factores de orden microbiológico, influenciados por la práctica de aseo, de desinfección y de higiene ambiental, al momento del ordeño (Hurtado et al. 2005b). Se acepta que la calidad higiénica medida en Unidades Formadoras de Colonias (UFC/Ml) debe ser inferior a 100.000 UFC. La Resolución 000017/12 establece los rangos de bonificación y de sanción y los procesadores lácteos bonifican recuentos inferiores a 30.000 UFC/mL (Gaviria, 2007).

Este trabajo, se realizó para contribuir al conocimiento sobre la calidad higiénica y sanitaria de la leche de búfalas y los factores de riesgo y de protección al que es sometida la leche, en todas las fases de la rutina de ordeño.

\section{MATERIALES Y MÉTODOS}

Población de hatos Bufaleros: Se analizaron 23 ordeños bufaleros, 14 ubicados en la Costa Atlántica y 9 en el Magdalena Medio, socios de la empresa Cooperativa Lechera de Antioquia (Colanta), con características, como tener un tanque de enfriamiento y seguimiento a la calidad higiénica y sanitaria disponible en la base de datos de la cooperativa. Se solicitó el consentimiento de los propietarios de los hatos y aval de la Asociación Colombiana de Bufalistas (ACB), como respaldo y reconocimiento de la importancia de la investigación.

Aplicación de lista de chequeo y toma de muestras: La lista de chequeo fue diseñada teniendo como guía el artículo 6 del Decreto 616 de 2006. Se desarrollaron pruebas piloto en hatos bovinos (vacas y búfalas) para identificar y para corregir posibles errores en la estructura, el lenguaje y la búsqueda de información de la lista de chequeo, hasta lograr la versión definitiva.

Durante las visitas a los hatos, se realizaron, al menos, dos observaciones del ordeño de principio a fin, mientras se llenaba la lista de chequeo. Se tomaron muestras pareadas de leche en tanque, bajo las indicaciones reportadas por la Unidad de Diagnóstico del laboratorio de Calidad e Inocuidad de Leche Cruda de la Universidad de Antioquia (Toro, 2012).

Se utilizaron frascos estériles con conservante Azidiol, para las muestras usadas en la determinación de Unidades Formadoras de Colonias UFC, con el bactoscan y con Bronopol, para las muestras dirigidas al Recuento de Células Somáticas, (RCS). Se depositaron las muestras en neveras con geles conservantes, para asegurar refrigeración de la muestra a $4^{\circ} \mathrm{C}$, hasta la remisión a los laboratorios. Las muestras, tanto para UFC como para RCS, se enviaron al Laboratorio de calidad e inocuidad de la leche de la cooperativa acopiadora.

Análisis de Laboratorio: El análisis, se realizó mediante el uso de equipos con tecnología de citometría de flujo, Bactoscan para UFC y Combifoss para RCS, los cuales, están calibrados bajo metodologías internacionales de referencia AOAC 986.33, BS ISO 21187 (IDF 196, 2004), para bacterias mesófilos aerobias y la ISO 13366-1, 2008 (IDF 148-1, 2008), para células somáticas.

Análisis estadístico: Se realizó un análisis descriptivo para cada una de las variables contempladas en el estudio. Para determinar los factores de riesgo o protección de la rutina de ordeño que influyen sobre los recuentos de UFC y RCS, se efectuó el cálculo de riesgo relativo (OR) y los valores de $P$ para cada una de las variables, para determinar el grado de asociación y se practicó una prueba de chi cuadrado de Pearson, con nivel de significancia de 95\%, con el programa estadístico SPSS 18.0.

\section{RESULTADOS Y DISCUSIÓN}

Caracterización de la rutina de ordeño: En la caracterización de la rutina de ordeño de los hatos bufaleros, se construyeron tablas de frecuencias con las variables indagadas en la lista de chequeo. Con el resultado de las tablas de frecuencias, de la estimación de riesgo con $\mathrm{OR}$, de las observaciones hechas en el trabajo de campo y teniendo en cuenta la 
caracterización realizada por Ramón et al. (2011) y Posada et al. (2010), se diseñaron diagramas de flujo de las prácticas pre-ordeño, del proceso de aseo del ordeñador, de las activi- dades durante y post-ordeño y de la disposición de la leche post-ordeño en los hatos visitados (Figuras 1, 2, 3 y 4).

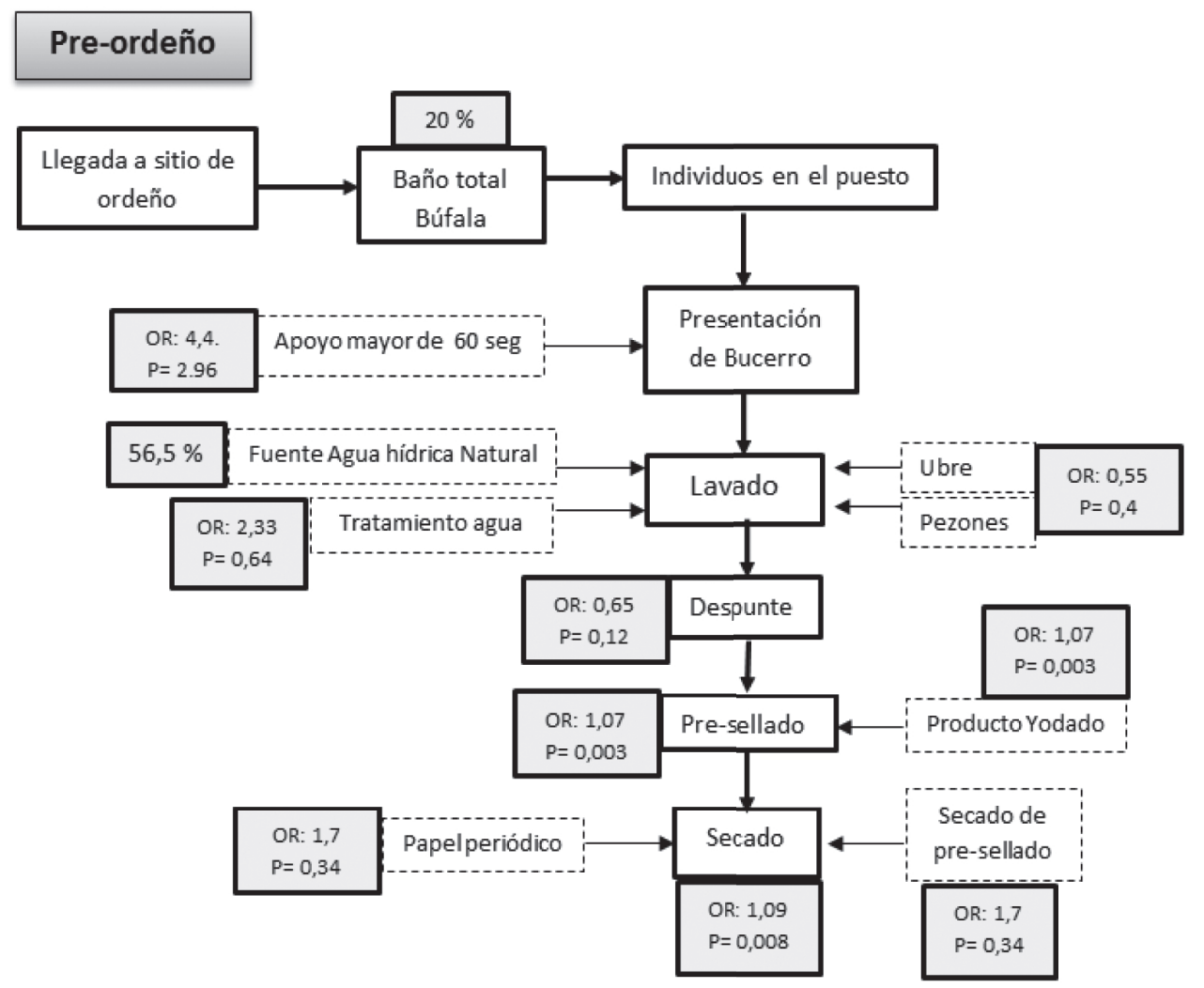

Figura 1. Flujograma de las prácticas pre- ordeño, en hatos bufaleros del Magdalena Medio y Costa Atlántica colombiana. Los cuadros de color blanco representan la fase de la rutina de ordeño; los cuadros punteados son características de cada fase; los cuadros color gris representan el OR y valor de p en UFC o el porcentaje del indicador en el total de los hatos evaluados.

\section{Aseo ordeñador}

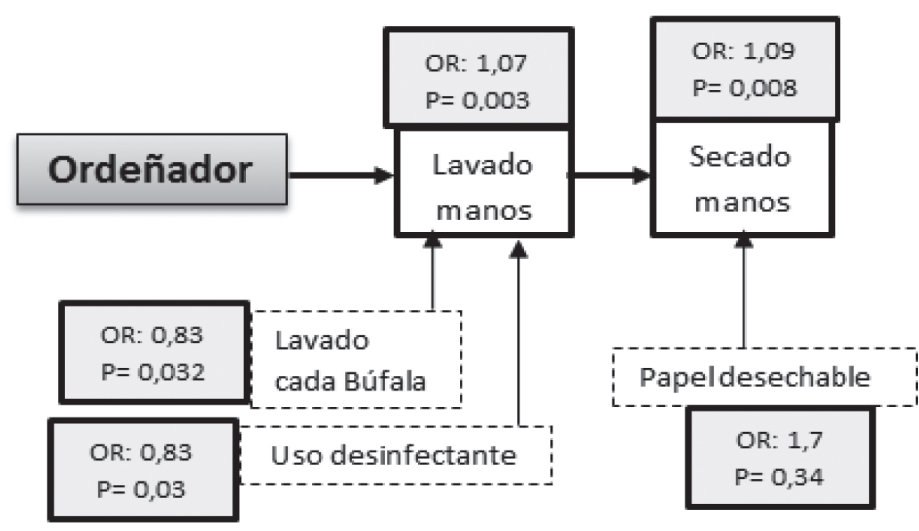

Figura 2. Flujograma del proceso de aseo del ordeñador, en hatos bufaleros del Magdalena Medio y Costa Atlántica colombiana. El cuadro color blanco representa la fase de la rutina de ordeño; el cuadro punteado son características de cada fase; los cuadros pequeños en color gris representan el OR y valor de p en UFC o el porcentaje del indicador en el total de los hatos evaluados. 


\section{Rutina de Ordeño y Pos-ordeño}

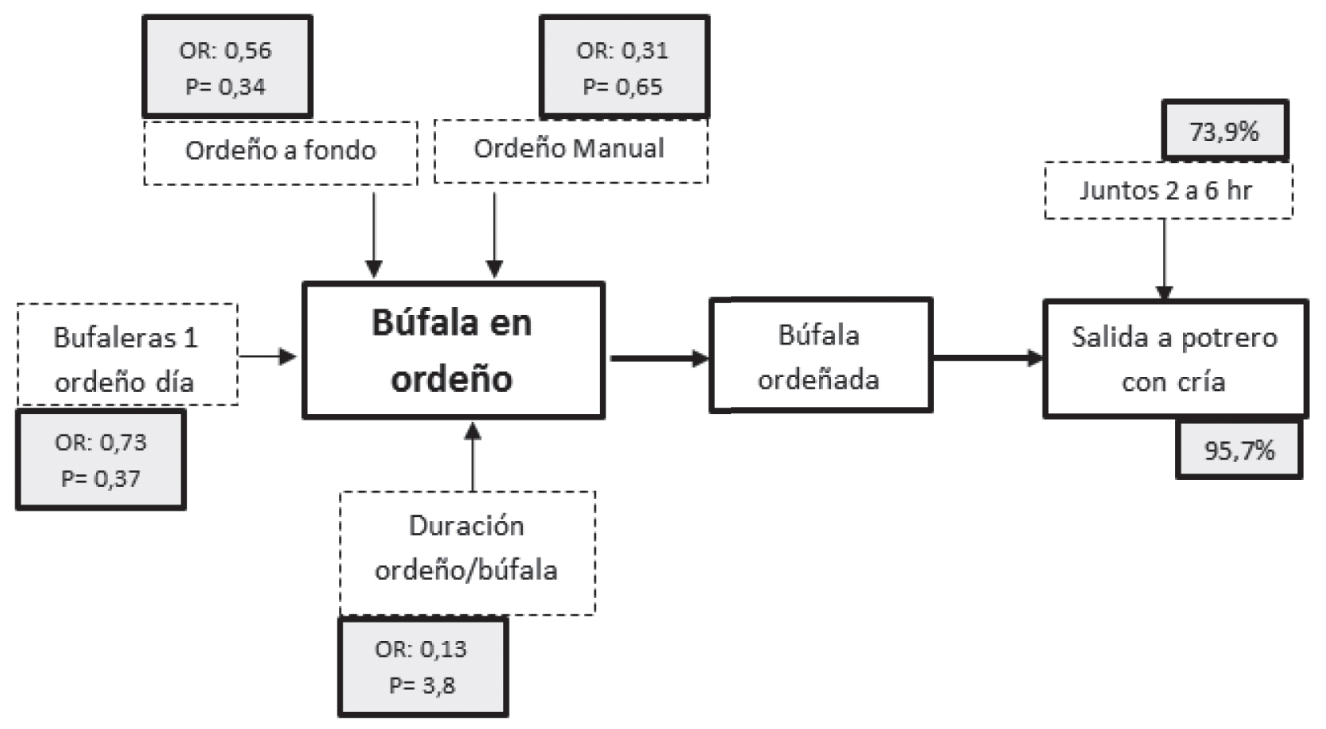

Figura 3. Flujograma de la rutina durante y después del ordeño, en hatos bufaleros del Magdalena Medio y Costa Atlántica colombiana. El cuadro color blanco representa la fase de la rutina de ordeño; el cuadro punteado son características de cada fase; los cuadros pequeños en color gris representan el OR y valor de p en UFC o el porcentaje del indicador en el total de los hatos evaluados.

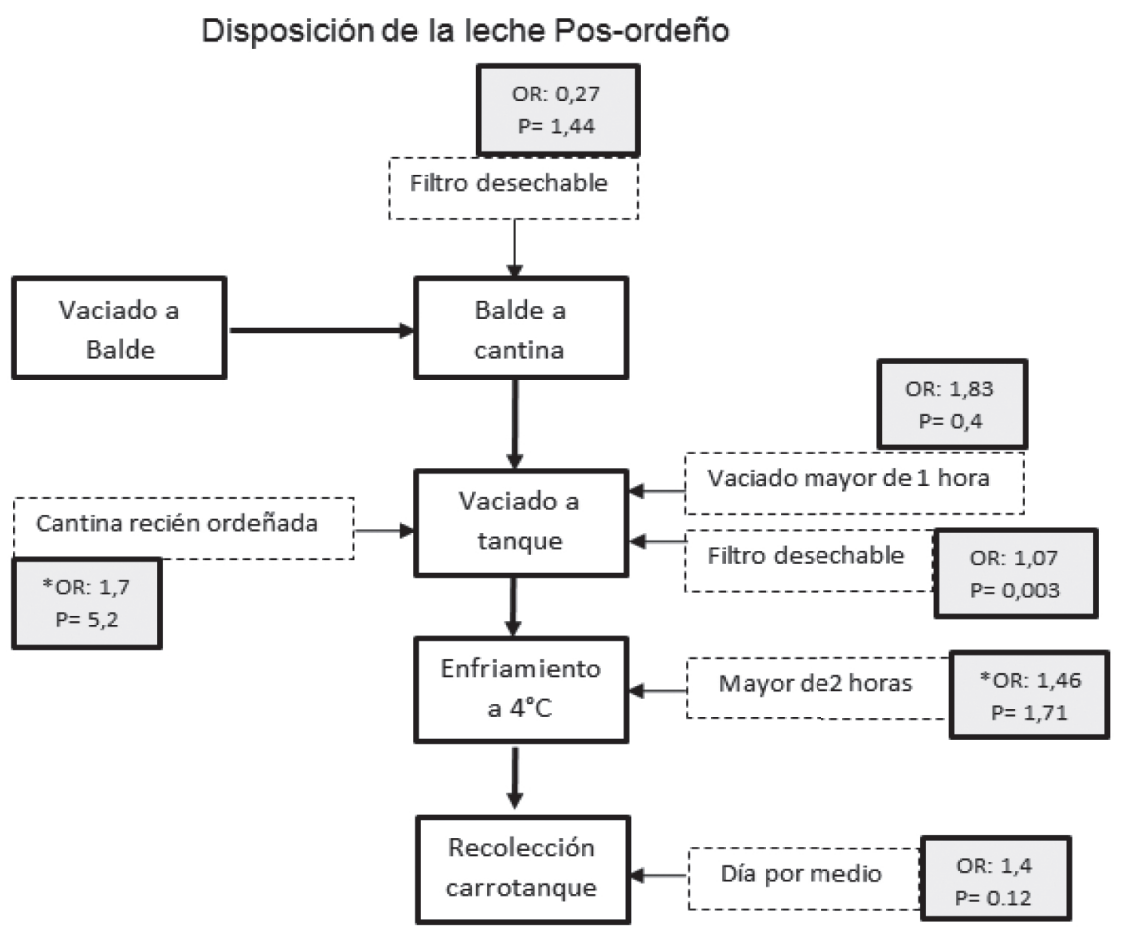

Figura 4. Flujograma del proceso de disposición de la leche, en hatos bufaleros del Magdalena Medio y Costa Atlántica colombiana. El cuadro color blanco representa la fase de la rutina de ordeño; el cuadro punteado son características de cada fase; los cuadros pequeños en color gris representan el OR y valor de p en UFC o el porcentaje del indicador en el total de los hatos evaluados.

*Indica el valor de OR, como factor de protección, a bajos recuentos de UFC. 
Calidad higiénica y sanitaria: Del análisis de bases de datos de la industria láctea para las primeras 21 semanas (eneromayo) de 2013, los hatos en el Magdalena Medio presentan un promedio de $310,0 \pm 301,35 \times 10^{3} \mathrm{UFC} / \mathrm{mL}$ y un promedio de RCS $162,7 \pm 36,5 \times 10^{3} \mathrm{sc} / \mathrm{mL}$. Para la Costa Atlántica, el promedio de UFC fue de 97,4 \pm 189,17 x 103UFC/ $\mathrm{ml}$ y en RCS 119,6 $\pm 37,94$ x 103cs/mL. Resultados no muy distantes de los encontrados en el estudio.

Análisis de las bufaleras: El resultado de calidad higiénica de leche en tanque presenta una mediana de $42 \times 10^{3} \mathrm{UFC} / \mathrm{ml}$ (comprendida en un rango de 3 a $1351 \times 10^{3} \mathrm{UFC} / \mathrm{mL}$ ), valor que se encuentra en el rango de bonificación, de acuerdo a la Resolución № 000017 de 2012, del Ministerio de Agricultura.

La calidad sanitaria, se bonifica de forma voluntaria, por lo tanto, se consideró el rango que ofrece la cooperativa que es sobre recuentos menores de $200.000 \mathrm{cs} / \mathrm{ml}$ (para la Resolución 000017 de 2012 las bonificaciones de RCS son voluntarias y discrecionales de la empresa); se obtuvo una mediana de $69 \times 10^{3} \mathrm{cs} / \mathrm{mL}$ (comprendida en un rango de 12 a 585 x $103 \mathrm{cs} / \mathrm{mL}$ ), resultados, en los cuales, reciben bonificación por calidad.

Con respecto a la asociación de los altos recuentos de UFC y RCS a las prácticas de ordeño, se demostró que un 30,4\% de los hatos presentan altos recuentos (superiores a 300.000 UFC/mL y $200.000 \mathrm{cs} / \mathrm{mL}$ ).

Los factores de riesgo (OR) fueron calculados para identificar los pasos en la rutina de ordeño que influyen sobre la calidad higiénica y sanitaria de la leche, además factores protectores que permiten disminuir el riesgo en las tres fases del ordeño analizadas, presentados en las tablas 1 y 2 .

Tabla 1. Factores de riesgo asociados a altos recuentos de Unidades Formadoras de Colonias (UFC), en ordeño de búfalas.

\begin{tabular}{|l|l|l|l|}
\hline \multicolumn{1}{|c|}{ Indicador } & \multicolumn{1}{c|}{ OR } & \multicolumn{1}{c|}{ Valor de $\mathbf{p}$} & \multicolumn{1}{c|}{$\mathbf{9 5 \%}$ IC } \\
\hline Ausencia tratamiento de agua & 2,33 & 0,64 & $0,28-19,17$ \\
\hline Falta de lavado de manos & 1,7 & 0,003 & $0,09-12,8$ \\
\hline Falta de secado de manos & 1,09 & 0,008 & $0,15-7,8$ \\
\hline Material para secado de manos & 1,07 & 0,34 & $0,25-12,45$ \\
\hline Ausencia de Pre-sellado & 1,07 & 0,003 & $0,9-12,8$ \\
\hline Ausencia de filtrado en tanque & 1,07 & 0,003 & $0,9-12,8$ \\
\hline Tiempo entre ordeño y vaciado a tanque & 1,83 & 0,4 & $0,28-12,07$ \\
\hline Frecuencia de recolección de leche & 1,4 & 0,12 & $0,19-9,87$ \\
\hline Frecuencia lavado y desinfección de tanque & 1,4 & 0,12 & $0,19-9,87$ \\
\hline
\end{tabular}

Tabla 2. Factores de riesgo asociados a altos recuentos en Células Somáticas (RCS), en ordeño de búfalas.

\begin{tabular}{|l|l|c|l|}
\hline \multicolumn{1}{|c|}{ Indicador } & \multicolumn{1}{|c|}{ OR } & Valor de $\mathbf{~}$ & \multicolumn{1}{c|}{$95 \%$ IC } \\
\hline Ausencia tratamiento de agua & 1,73 & 0,28 & $0,22-13,67$ \\
\hline Ausencia de vigilancia rutinaria de mastitis (CMT) & 2,93 & 1,37 & $0,47-18,33$ \\
\hline Fuente de agua para lavado & 1,47 & 0,46 & $0,1-1,95$ \\
\hline Material para secado de manos & 1,04 & 0,002 & $0,17-6,23$ \\
\hline Frecuencia de lavado de manos & 3,6 & 1,24 & $0,35-37,6$ \\
\hline Ausencia de despunte & 1,73 & 0,28 & $0,22-13,67$ \\
\hline Permanencia búfala-cría mayor de 6 horas & 2 & 0,33 & $0,18-22$ \\
\hline Ausencia de tratamiento de secado & 3,67 & 2,39 & $0,19-9,87$ \\
\hline Tiempo entre ordeño y enfriamiento a $4^{\circ} \mathrm{C}>2$ horas & 1,58 & 2,11 & $0,19-9,87$ \\
\hline
\end{tabular}


Los resultados analizados a la calidad de la leche que se produce en las bufaleras estudiadas son, en general, excelentes y susceptibles de bonificación. Si en cada una de ellas implementan en la rutina de ordeño aquellos pasos que les hacen falta y que se encontraron como factores de riesgo o mejoran sus procesos de control en sanidad, es posible que obtengan un mayor incremento en las bonificaciones.

Los recuentos de células somáticas podrían indicar que, aparentemente, las búfalas sufren menos mastitis que las vacas lecheras, cuando se comparan los promedios de la zona $137.100 \mathrm{cs} / \mathrm{mL}$ y 373.000 cs/mL (Vásquez et al. 2012), respectivamente.

Estudios previos en búfalos han reportado altos incrementos en el recuento de células somáticas en leche, debido a infecciones en la glándula mamaria, que desencadenan en mastitis (Sharif et al. 2007). La clasificación de afectación de la ubre, tomando como guía los conteos de células somáticas, han permitido establecer rangos de pérdida de producción de leche y pérdidas económicas en vacas (Hernández \& Bedolla, 2008), que hacen importante la vigilancia de este indicador en búfalas. Syed et al. (2009) mencionan que conteos menores a 250.000 células $/ \mathrm{mL}$ en leche de búfala son considerados como glándula mamaria sana, lo mismo Guha et al. (2012), cuando hace referencia a la organización internacional National Mastitis Council, que define que la mastitis subclínica se presenta cuando hay RCS iguales o superiores a 200.000 cell $/ \mathrm{mL}$ y se considera leche normal a conteos alrededor de $100.000 \mathrm{cell} / \mathrm{mL}$, al igual que lo referencia Dhakal (2006).

En Colombia, la resolución 000017/2012 deja a consideración de la industria la bonificación y la estimación de rangos de RCS, los cuales, oscilan entre 0 a $<200.000,200.001$ a $<400.000 \mathrm{cell} / \mathrm{mL}$ y mayores a este valor no se bonificaría la leche. Para el trabajo fueron considerados estos rangos, de forma tal que los resultados puedan servir como guía a productores e industria. Según Vásquez et al (2012), en Colombia, los menores RCS han sido encontrados en la región de trópico bajo, Planeta Rica (Córdoba), región donde se concentran una gran cantidad de empresas bufaleras.

Según Santana \& Uribe (2009), para reducir las UFC, se deben vigilar las normas de higiene en todas las acciones del ordeño, recomendación que se corrobora con los resultados encontrados en el trabajo, por tanto, se sugiere tener en cuenta los diagramas de flujo de la rutina de ordeño. Se logra una mejor calidad microbiológica evitando la contaminación con gérmenes ambientales y fecales, al procurar la ausencia de enlodamiento (Navarro et al. 2011), aunque los recuentos bacterianos encontrados son muy bajos en los ordeños manuales de búfalas, tal como lo reporta Briñez et al. (2000).
Del análisis de la información resultante, la identificación de actividades en las tres fases de la rutina de ordeño permitió un seguimiento secuencial de aseo, uso de insumos y manipulación de la leche.

El acompañamiento del bucerro, como estímulo para la producción-descenso de la leche, suprime el despunte, en el $78,3 \%$ de los ordeños y el pre-sellado, en $17,4 \%$ (observado y consignado en la lista de chequeo). El ordeñador no debe omitir el lavado de pezones, el despunte y el pre-sellado en la rutina de ordeño, bajo la creencia de que el bucerro, luego de mamar, deja limpio el pezón; en este trabajo, se detectó que esta omisión representa un factor de riesgo para la presencia de altos conteos de UFC.

El 91,3\% de los ordeños evaluados en el estudio son de tipo manual. Bajos estas condiciones, las acciones de manipulación de la leche y el tiempo que se tardan para su almacenamiento en tanque, se elevan. Sumado a esto, la exposición a factores locativos (distancia entre lugar de ordeño y cuarto tanque), transporte de cantinas a mitad-final del ordeño y temperatura ambiental alta, mantienen un óptimo rango para mesófilos (Posada et al. 2010) y aumentan el riesgo de afectar la calidad final del producto. Por tanto, se debe disminuir el tiempo transcurrido entre el ordeño, el transporte de las cantinas hasta el almacenamiento y la conservación en tanque.

En cuanto a la calidad higiénica, los recuentos bacterianos encontrados están muy cerca del límite de calidad bonificable y la desviación estándar permite evidenciar recuentos superiores al promedio, los cuales, de acuerdo a la normatividad vigente, debe recibir sanción.

La calidad sanitaria analizada, luego de la aplicación de la lista de chequeo y en la base de datos, evidencian niveles deseables de RCS, inferiores a $200.000 \mathrm{cs} / \mathrm{mL}$, pero algunos datos superaron este rango, lo que permite deducir que los programas de control, como la vigilancia rutinaria de mastitis (CMT), la cual, es efectuada sólo por el $39,1 \%$ de los ordeños y debe ser indiscutiblemente parte de la práctica de ordeño y merecedora de investigación, sobre los factores que la modifican o alteran.

Los promedios generales de UFC y RCS encontrados en leche de tanques de enfriamiento indican que la leche de búfala evaluada es de buena calidad. Estos valores están cercanos a los límites de bonificación de calidad. Aunque esta leche es acopiada por la industria láctea para el consumo humano, la identificación de aquellas actividades o factores de riesgo en la rutina de ordeño, se permitiría que su calidad mejorara aún más, con la implementación de las buenas prácticas de producción de leche (Correa, 2005) y el aumento del nivel de formación de los ordeñadores, tal como lo 
indican Ng et al (2010).

De los resultados presentados, se concluye que para mantener bajos conteos de UFC, los ordeños evaluados deben estimular el lavado y el secado de las manos del ordeñador, realizar el pre-sellado, usar filtro en los tanques (acciones que se presentan como factores de riesgo con $p<0,05$ ), además, de acortar el tiempo entre el ordeño y el vaciado de la leche en el tanque, garantizar la recolección frecuente de la leche por el carro-tanque e instaurar un programa de lavado y de desinfección frecuente del tanque de enfriamiento. Estas medidas higiénicas son indispensables, debido a las características de esta especie a revolcarse en lodazales y charcas (Hernández \& Espinosa, 2005).

Para obtener bajos RCS, los ordeños se deben incluir en la rutina de ordeño la vigilancia de mastitis mediante CMT, vigilar el material con el que se realiza el secado de las manos del ordeñador, incluir el despunte, usar filtro en los tanques, garantizar la permanencia del bucerro con la búfala no más de 6 horas y realizar el tratamiento de secado.

Agradecimiento: Agradecimientos a la Estrategia de sostenibilidad 2013-2014 de la Universidad de Antioquia, al laboratorio de calidad e inocuidad de leche de la Facultad de Ciencias Agrarias y a COLANTA, por el apoyo a este trabajo. Conflicto de intereses: Los autores declaramos que no existe ningún conflicto de interés que ponga en riesgo la validez de los resultados presentados

\section{BIBLIOGRAFÍA}

1. BRIÑEZ, W.; MORELO, E.; VILLALOBOS, C.; MONTIEL, N.; VALBUENA, E.; CASTRO, G.; URDANETA, S. 2000. Parámetros de calidad y géneros bacterianos más frecuentes en leche cruda de Búfala en el municipio de Mara, estado de Zulia. Rev. Científica, FCVLUZ. 10(4):346-352. Disponible desde Internet en: http://www.saber.ula.ve/handle/123456789/27392 (con acceso 18/03/2012).

2. CERVANTES, E.; ESPITIA, A.; PRIETO, E. 2010. Viabilidad de los sistemas bufalinos en Colombia. Rev. Col. Cienc. Anim. 2(1). Disponible desde Internet en: http://dialnet.unirioja.es/descarga/articulo/3268865. pdf. (con acceso 18/03/2012).

3. COLANTA. 2012. Mejores pagos de leche semana 17. Rev. ECOLANTA (Colombia). 245 mar-abr. p.35.

4. COLOMBIA. MINISTERIO DE AGRICULTURA Y DESARROLLO RURAL. Resolución 000017 de 2012.
5. COLOMBIA. MINISTERIO DE LA PROTECCIÓN SOCIAL. Decreto Número 616 de 2006.

6. CORREA, H. 2005. Código de buenas prácticas de producción de leche para Colombia. Universidad Nacional de Colombia, sede Medellín. Disponible desde Internet en:http://www.slideshare.net/JuanDavid28/ codigo-colombiano-de-buenas-practicas-de-manejo-en-el-ordeo (con acceso 23/03/2012).

7. DHAKAL, IP. 2006. Normal somatic cell count and subclinical mastitis in murrah buffaloes. J Vet Med B Infect Dis Vet Public Health (Berlin). 53(2):81-86. Disponible desde Internet en: http://www.ncbi.nlm.nih. gov/pubmed/16626405 (con acceso 23/03/2013).

8. FAO. 2010. FAOSTAT. Agriculture Database. FAO (Roma). Disponible desde Internet en: http:// faostat.fao.org/DesktopModules/Admin/Logon. aspx?tabID $=0$ (con acceso 18/03/2012).

9. GAVIRIA, B. 2007. Calidad higiénica y sanitaria de la leche cruda. Sección 3, calidad composicional, higiénica y sanitaria: capítulo 11. Ed. Biogénesis, Universidad de Antioquia. p.115-122.

10. GUHA, A.; GUHA, R.; GERA, S. 2012.Comparison of somatic cell count, California mastitis test, chloride test and rennet coagulation time with bacterial culture examination to detect subclinical mastitis in riverine buffalo (Bubalus bubalis). Afr. J. Agric. Res. 7(41):5578-5584. Disponible desde Internet en: http://www.academicjournals.org/article/article1380907431_Guha\%20et\%20al.pdf (con acceso 19/06/2013).

11. HERNÁNDEZ, R.; BEDOLLA, J. 2008. Importancia del conteo de células somáticas en la calidad de la leche. Rev. REDVET. (España). 9(9):1-34. Disponible desde Internet en:http://www.veterinaria.org/revistas/redvet/ n090908/090904.pdf_(con acceso 07/04/2012).

12. HERNÁNDEZ, R.; ESPINOSA, Y. 2005. Ordeño de las búfalas: manejo, rutina y consideraciones prácticas. Rev. ACPA (Cuba). (1):16-17

13. HURTADO, N.; CERÓN, M.F.; TONHATI, H.; GUTIÉRREZ, A.; HENAO, A. 2005a. Producción de leche en Búfalas de la Costa Atlántica Colombiana. Livest. Res. Rural. Dev. Online (Colombia).17(12).

14. HURTADO, N.A.; CERÓN, M.F.; LOPERA, M.I.; BERNAL, A.; CIFUENTES, T. 2005b. Determinación de 
parámetros físico-químicos de leche bufalina en un sistema de producción orgánica. Livest. Res. Rural. Dev.17(1).

15. ISO 21187, IDF 196. 2004. Milk Quantitative determination of bactiorological quality. Guidance for establishing and verifying a conversion relationship between routine method results and anchor method results. ISO (Switzerland).

16. NAVARRO, J.M.; NOVOA, R.M.; CASANOVAS, E. 2011. Evaluación de parámetros de calidad de la leche bufalina al final de la lactancia en la provincia de Cienfuegos. Rev. REDVET. (España). 12(6):1-10. Disponible desde Internet en: http://www.redalyc.org/articulo. oa?id=63622160007 (con acceso 22/06/2013).

17. NG, L.; JOST, C.; ROBYN, M.; DHAKAL, I.; BETT, B.; DHAKAL, IP.; KHADKHA, R. 2010. Impact of livestock hygiene education programs on mastitis in smallholder water Buffalo (Bubalus bubalis) in Chitwan, Nepal. Prev. Vet. Med. (Netherlands). 96(34):179-185.

18. PATIÑO, E. 2011. Producción y calidad de la leche bubalina. Rev. Tec en Marcha (Costa Rica). 24(5): 25-35.

19. POSADA, S.; LOAIZA, E.T.; RESTREPO, J.E.; OLIVERA, M. 2010. Caracterización del ordeño manual e identificación de puntos críticos de control para la calidad higiénica de la leche en una finca lechera del norte de Antioquia. Rev. Lasallista Investig. (Colombia). 7(2):35-46.

20. RAMÓN, J.N.; RESTREPO, J.E.; RUIIZ, Z.T.; OLIVERA, M. 2011. Detección de riesgos de contaminación con microbios ambientales en un sistema de ordeño mecánico de un hato lechero del norte de Antioquia. Rev. Lasallista Investig. (Colombia). 8(1):7-15.
21. SANTANA, R.; URIBE, C. 2009. Rutina de ordeña y calidad higiénica de la leche. Boletín Inia. (148):1-8. Instituto de Investigaciones Agropecuarias, Centro Regional de Investigación Remehue. Disponible desde Internet en: http://www2.inia.cl/medios/biblioteca/boletines/NR33845.pdf fecha de consulta 07/04/2012 (con acceso 07/04/2012).

22. SHARIF, A.; AHMAD, T.; BILAL, M.Q.; YOUSAF, A.; MUHAMMAD, G. 2007. Effect of severity of sub-clinical mastitis on somatic cell count and lactose contents of buffalo milk. Pak. Vet. J. 27(3):142-144.

23. SYED, A.M.; DIGRASKAR, S.U.; AWAZ, K.B. 2009. Evaluation of buffalo milk with reference to somatic cell conunt and antitrypsin. Vet. World. (India). 2(7):267268.

24. TORO, C. 2012. Protocolo de toma de muestras de leche: laboratorio de calidad e inocuidad de leche cruda. Facultad de Ciencias Agrarias, Universidad de Antioquia, Colombia. Disponible desde Internet en: http://www.udea.edu.co/portal/page/portal/bibliotecaSedesDependencias/unidadesAcademicas/ FacultadCienciasAgrarias/BilbiotecaDiseno/Archivos/DocsVarios/TomaMuetrasLeche.pdf (con acceso 04/03/2013).

25. VÁSQUEZ, J.F.; LOAIZA, E.T.; OLIVERA, M. 2012. Calidad higiénica de leche cruda acopiada en diferentes regiones Colombianas. ORINOQUIA (Colombia). 16(2):13-23.

26. VÁSQUEZ, J.F. 2005. Caracterización de la explotación del búfalo (Bubalus bubalis) en Colombia. Parte II. Despertar Lechero (Colombia). 24:54-68.

Recibido: Octubre 17 de 2013

Aceptado: Enero 29 de 2014

Como citar:

Morales Morales, S.A.; Rodríguez, N.; Vásquez, J.F.; Olivera Ángel, M. 2014. Influencia de la práctica de ordeño sobre el recuento de células somáticas (RCS) y unidades formadoras de colonias (UFC) en leche bufalina. Rev. U.D.C.A Act. \& Div. Cient. 17(1): 189-196. 